\title{
Horrors Of Baby Making (Consequences Of Reproductive Technology On Humanity)
}

\author{
Asma Manzoor \\ \& \\ Saba Imran Ali \\ Women's Studies \\ University of Karachi
}

\begin{abstract}
"We are mainly responsible for our own evolution. Human evolution no longer proceeds as a result of chance and natural selection but through our personal and collective choices. Thus what we wish to become reflects above all the image we have of ourselves" (Rachael Hamed, 1997). Einstein once said, "We should be on our guard not to overestimate science and scientific methods when it is a question of human problems; and we should not assume that the experts are the only ones who have a right to express themselves on questions effecting the organization of society".
\end{abstract}

\begin{abstract}
The recent advances in the field of medical sciences have allowed the scientists to control the processes of life and death. These processes not only can prolong the human life by machines but doctors and scientists can also initiate the process of human life: artificial insemination, cloning, in vitro fertilization (IVF), cyropreservation of sperm, oocytes, embryos, embryo transfer (ET), hormone treatment, surrogacy, testicular sperm extraction (TESE) and gamete intra fallopian transfer (GIFT) are well known examples. By far the most common of these is IVF. As a result of these scientific innovation couples have become statistics and children have become scientific experiments. Technological advancement in biology not only raises the question of good or bad technology or good or bad effects of technology but it lead us to the question whether all works of science and technology are beneficial or otherwise for the humankind. Since the birth of Louis Brown in 1978 - the period related to the first 'test tube baby' in the UK, many ethical issues regarding reproductive technologies (RT) and their potential impacts on humanity at large have been raised. In the light of extraordinary medical and ethical consequences that the RT has placed on humanity in the developed world, a discussion has been made in the paper to identify and describe the reproductive technology: In Vitro Fertilization (IVF). This paper also explores the difficulties that Muslim countries like Pakistan could face when actual progression of reproductive technologies gets under way.
\end{abstract}

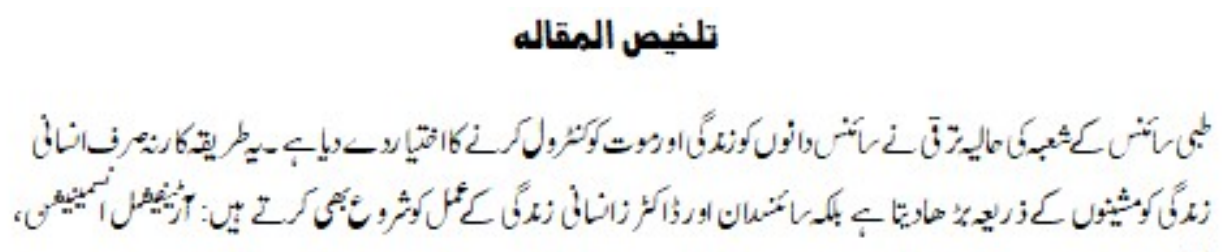

Artificial insemination, IVF, Cyropreservation of Sperm, Ooctyes, TESE, ، 


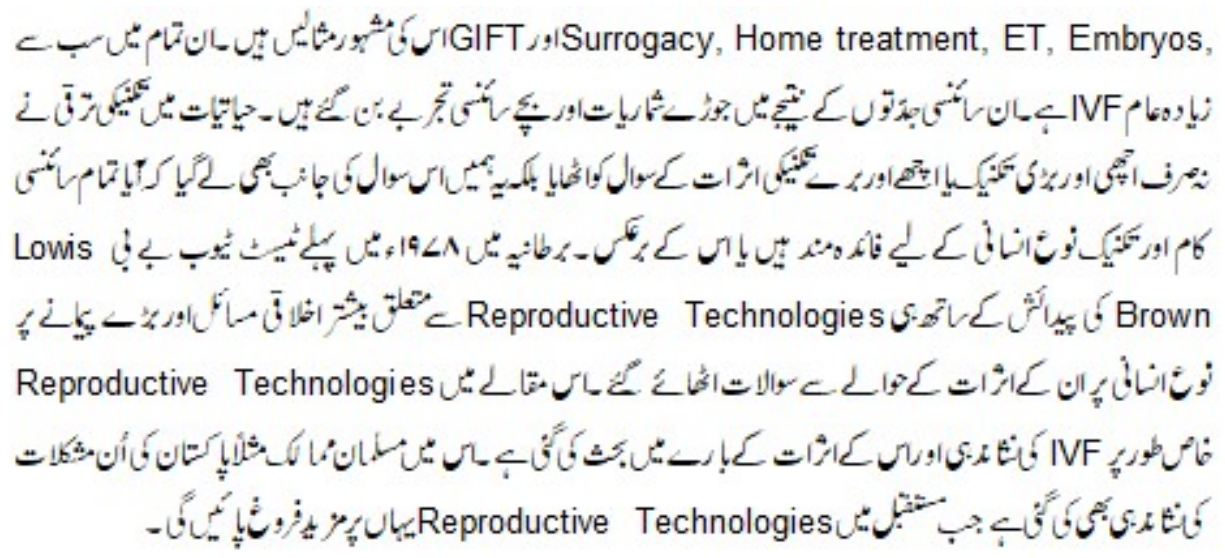

\section{Introduction}

In the last two decades, we have seen rapid increases in medical technologies designed to assist in reproduction. The term reproductive technology refers to medical innovations in the field of reproduction that either inhibit conception or facilitate conception. Developments in reproductive science have been a topic of fascination for scientists and society alike. From cyropreservation of human sperms, eggs and embryos to the rapeutic genetic modification in certain serious diseases this once described "miracle technology" is a term used to cover a whole range of advance techniques that the medical science has made in the field of infertility. These procedures are the only way through which a lot of desperate infertile couples can by pass the problems of infertility and can have a child of their own. Infertility means being unable to conceive a baby naturally after at least 12 months or according to WHO in some cases up to 24 months of regular sexual relationship. The causes can lie equally with a woman or a man and in $20 \%$ of couples infertility is unexplained or 'idiopathic' (YA,Wang 1996).

Earlier only two remedies were available for the infertile couples either to remain childless or adopt a baby. Where as remain childless is a legitimate choice made by most of the couples. Number of women and men experience strong desire to have a child of their own and this inability can be devastating and involve a lengthy process of loss and grief.

Reproductive technology is an important issue for women as it relates directly to their bodies, to their health and as well as their role in society. During 1960 the introduction of artificial birth control, especially the birth control pills created a huge medicine market. Couples were getting aware that they could control their reproductive years through these pills and children could be postponed. In late 1970's significant reproductive technological advancements have changed the way women can have children, and even 
definitions of motherhood and fatherhood. However, it does have its drawbacks also. The success rate is relatively low and most couples have to go through extensive infertility evaluation and treatments before they are considered for utilizing these highly sophisticated techniques of conception and the treatments can be both financially and emotionally draining. There are ongoing debates also about the ethical, moral, legal and religious dimensions of these technologies. On the other side the relative rate at which the RT has increased is also quite high, and since 1978, eight new technologies have been discovered besides In Vitro Fertilization (IVF) (Assisted Reproductive Technology, 2007).

\section{Infertility and In Vitro Fertilization}

Patrick Steptoe and Robert Edwards are the pioneers to bring into function of IVF and in result Louis Brown; the world's first test-tube baby was born in Britain. Since then IVF has spread around the globe and reaching countries far from the technology producing nations of the west; perhaps nowhere is this globalization process more evident than in the nearly twenty nations of the Middle East, where the IVF industry is flourishing. As of 2003, Egypt boasted nearly 50 IVF centers, Israel nearly 25 and Lebanon nearly 15. Given the relatively small populations of both Israel and Lebanon, these are among the highest per capita numbers of IVF centers in the world (Inhorn, 2003).

IVF is used to mainly to overcome female infertility. It is due to damaged, diseased or absent of fallopian tubes, in which the egg can not pass to reach the uterus. It may be used to treat other forms of infertility, for instance where a woman does not produce eggs, for this donated eggs are used and a new baby is made possible (Fertility Treatment: 2007).

"IVF- means literally fertilization of an egg outside, rather than inside a woman's body". The concept of IVF is quiet simple. A woman is given hormones to stimulate ovulation so that several eggs can be produced during the monthly cycle. These eggs then removed from her ovary and put into sterile laboratory dish or tube with live sperm so that fertilization can occur. After fertilization occurs the embryo or embryos (egg) are transferred to the uterus where it may implant itself in the lining of her womb and continue to develop normally. This treatment was first developed for women with serious damage to their fallopian tubes. There are several types of IVF, depending on whether the woman or man is the cause of the infertility and how severe it is (Richardson, 1993).

Though simple in theory but a complicated procedure in practice and requires very precise timing and careful controlled condition, to result in pregnancy. Very often IVF can not occur, and overall success rate is also very low, only one woman out of ten can have a child. 
These technologies are the medical manipulation of women's bodies which also increases the risks of premature births, multiple pregnancies and associated dangers for the mother and babies. IVF can be a very stressful procedure to encounter. When a woman is operated to remove eggs, she must wait to find out the outcome of each stage of the process. It causes physical as well as psychological stress to the respective woman. Anxiety, depression, sadness, and anger are common reactions to this stress (National Health \& Medical Council, 1995). After a successful IVF attempt, IVF parents experience more stress during the pregnancy than parents dealing with a naturally conceived pregnancy do. There have been numerous studies related to the current health of the patients and their offspring. These reports suggest a number of troubling things. Firstly, ovarian and breast cancer have been linked to the use of hormonal stimulation necessary for most methods (Ness, 2000). According to the study directed by the St. James Hospital in Leeds, England, multiple births as a result of reproductive technology treatment have led to many cases of blindness in the children born. The blindness is caused by a genetic defect and is treatable only if found within anywhere from days to 10 months after birth.

\section{Cost and Moral Dilemma}

For most of the countries (technically advanced) the average cost for utilizing the technique is alarming high. The average cost of a single IVF cycle is approximately $\$ 2,770$. Here it is important to note that for a successful treatment at least three cycles are required and the success rate too is very low (Infertility \& New Reproductive Technologies, 2007).

Surrogate ${ }^{1}$ parentage, egg and sperm donation are three aspects of this technology that presents several moral dilemmas. When donors are involved, reproductive technologies influence societal opinions concerning the morality of individuality and parenthood. We have both genetic parents and legal parents as well (Reproductive Technologies, 2007). For example, in the case of artificial

Insemination $^{2}$ the genetic father donates his sperm to another man's wife which is the genetic and legal mother. This raises the dilemma of which man is the child's legal father? Is it the husband of the genetic and legal mother or not? Which man will assume responsibility for supporting the child? In surrogate embryo transfer case, the genetic mother is often not the same as the gestational mother- each may also differ from the legally defined mother. If the rearing mother, who is most often also the gestational mother, is usually considered to be the primary mother, we need to examine what values are implicated here. On the religious and cultural attitudes pertaining to reproductive technology world wide there is a consensus of the great majority that these techniques were available to only the wealthy community and only to married couples. 


\section{In Vitro Fertilization and Islam}

Let's see the situation of the Muslim world, where infertile couples are extremely concerned about the dramatic advancement of making their babies in the religiously correct manner. For that purpose they are seeking 'fatwa' (official Islamic opinion) on the practice of IVF. IVF is concerned with the actualization of a potential human outside the womb. As such, it creates an interesting phenomenon when compared to the understanding of human creation as written in Quran. A verse in the Quran addresses Allah's creation of a human being inside the womb $(23: 12,13,14$ The Holy Quran, 1946).

"Man we did create from a quintessence (of clay). Then we placed him as (a drop of) sperm in place of rest, firmly fixed then we made the sperm into a clot of congealed blood; then of that clot we made a (foetus) lump; then we made out of that lump bones and clothed the bones with flesh; then we developed out of it another creation. So blessed be God, the best to create!"

At the beginning it can be said that the new techniques of IVF is morally trouble-free because it does not involve creation out of nothing which essentially is the work of Allah (42:50 The Holy Quran, 1946).

"He bestows (children) male or female according to His Will (and plan), or He bestows both males and females, and He leaves barren whom He Will: Foe He is full knowledge and power."

Doctors can make the first move of fertilization and assist in reproduction but Allah determines the eventual development and survival of the embryo. With this philosophical background it is easy not to acknowledge physicians as co-creators of children even though there may be major medical intervention in conception.

As one of several medical techniques in artificial human reproduction, the shariah holds that it is both appropriate and legal when performed using gametes of married couples (Nor, 1999).

As IVF research presents many features, it therefore demands an equally careful exercise of ethical considerations in the light of Islam and its objectives. IVF and its implications challenges the notion of how a nation can produce a society that has at its core a deep sense of religious consciousness, and is committed to the highest standards of ethical and moral values. A global survey of sperm donation among assisted reproductive technology centers in 62 countries provides some indications of the degree of convergence between

official discourse and actual practice. In all of the Muslim countries surveyed- including the Middle Eastern countries of Egypt, Iran, Kuwait, Jordan, Lebanon, Morocco, Qatar, 
and Turkey, as well as a number of non-Middle Eastern Muslim countries including Indonesia, Malaysia, and Pakistan- sperm donation in IVF and all other forms of gamete donation were strictly prohibited. As this global survey state, "In many Islamic countries, where the laws of Islam are the laws of the state, donation of sperm was not practiced. AID is considered adultery and leads to confusion regarding the lines of genealogy, whose purity is of prime importance in Islam"(Mierow, 1997).

\section{Situation in Pakistan}

Now discussing the situation in Pakistan where reproductive technology is a new development, the picture is rather unwelcoming. Pakistan also has few institutions providing reproductive technological techniques. These centers are situated in Lahore, Karachi and Islamabad. The success rate is of $20 \%$ and average cost of a single IVF cycle costs Rs.150,000 - 200,000; thus making the technique less accessible for most couple in need (Arshad, 2000). Now after arrival of reproductive technology the medical impact of the technique could be hazardous because we are a country which cannot even boast a well-equipped gynecology ward in most of its government and private hospitals. Because the technology is not yet advanced there are no known studies conducted that reports on medical problems due to IVF or other techniques on patients and offspring in the country.

Due to strong national religious belief the moral codes allowed for use of only the most simplistic methods of assisted reproduction, and even then, using the methods is a last option and frowned upon. According to a report published in DAWN (Arshad, 2000) most people exhibited the greatest objections to the use of reproductive technology and genetic engineering and were of a view that such techniques are unethical, interference with nature and Allah. Similarly fears like the baby may not be a couple's biological offspring create hindrance for both public and couples in need of the treatment. Answering to the queries of the legitimacy of such births a religious scholar, Justice Taqi Usmani informed that only those reproductive technological births are permissible in Islam that are conceived through the samples of the couple only and while they are married. While keeping in view the social, ethical and religious perspective he instantly denounced the idea of donor insemination and surrogate motherhood. Like wise the doctors who perform such techniques are against the use of donor sperms and eggs. Another matter of concern is our society's attitude towards test tube babies. Most of the couples who opt for these technological procedures want the fact to be remaining extremely confidential. According to a report published in Review (Schuklenk, 2000) in most of the cases no one in the couple's family knows that they are seeking treatment. Culturally there is a lot of pressure on childless couple particularly on women to produce but when these people go to reproductive technology treatments the fact is not looked upon them by very similar persons. All couples that were questioned were confused that they confided about the treatment even from their immediate family members. 
It is still unclear to what account these doctors are correct. What if in future experiments they require donor sperms or eggs? How our religiously constrained society wills see to that? Also when a new form of illegal crime of 'egg is trafficking' has occurred making billions of business in countries like Britain, can Pakistan with its corrupt law enforcement bring a firm grip to similar situation?

\section{Conclusion}

Internationally, Pakistan is prone to gender discrimination against female. Sons are prized here as a financial support for families whereas daughters are liability due to complex dowry - like marriages. Correlating to the issue of sex selection this technology will definitely lead to large numbers of female infanticide in the country due to child preferences. Like wise embryo selection testing too would pursue most couples to seek for 'super babies' as the production of their own interest.

In our opinion 'adoption' should be taken under consideration regardless on any cultural and religious belief as there are already many children as a result of war, natural disasters and unwanted pregnancies. Love and care are the two basic gestures that a child needs. Any individual regardless of her/his personal and social standing can provide a healthy environment for development for a child in need.

No doubt reproductive technology has brought many smiles in the lives of various desperate couples but the consequences under which it has flourished for over the past few decade is disastrous. Perhaps the best answer is to say that before things are taken any further, we stop to look at what we have, attempt to understand and evaluate them, and determine whether it is truly necessary to make advances in the technology. Perhaps we are at a point where the most important thing is to slow down the pace of change before it gets away from us.

\section{End Notes:}

${ }^{1}$ Surrogate mothers- woman who 'rent out' womb for women who are unwilling or unable to experience/carry a pregnancy. Just imagine - a donor egg and a donor sperm could be implanted into a surrogate mother, the baby then to be placed with another.

${ }^{2}$ IVF is seen in the same light as artificial insemination.

\section{References:}

Arshad, Ambreen. (7-13 Nov., 2000). “The Art of Life” In The Review weekly, Dawn, Karachi.

Assisted Reproductive Technology (ART), Retrieved on Nov.14, 2007 http://www.womhealth.org.au/infertility.htm. 
Fertility treatment Assisted Reproductive Technologies, Retrieved on Oct.01, 2007 http://www.womhealth.org.au/infertility.htm.

Hamed, Rachael. (1997) Human rights and Assisted Human Reproduction, Retrieved on Nov.22, 2007

www.hrc.co.nz/index.php?p=13681\&format=print\&id=13735\&keywords $=\&$ mont $\underline{\mathrm{h}=\& \text { year }=\& \text { Submit }=-12 \mathrm{k}}$

Infertility \& New Reproductive Technologies, Retrieved on Nov.14, 2007 http://www.womhealth.org.au/infertility.htm.

Inhorn, Marcia. (2003) Local babies, Global science: Gender, religion, and In Vitro Fertilization in Egypt, Routledge, New York.

Mierow, D., and J.G. Schenker. (1997) “The current status of sperm donation in assisted reproduction technology: ethical and legal" In Journal of Assisted Reproduction and Genetics, Springer, Netherlands, Vol.14, number 3.

National Health and Medical Research Council (1995) Long-term Effects on Women from Associated Conception. AGPS, Canberra , p 14-15.

Ness, R.B. et.al. (2000) Infertility, Fertility Drugs and Ovarian cancer: A pooled Analysis of Case Control Studies, In American journal of Epidemiology, vol. 155 No 3. pp. 217-24.

Nor, Siti Nurani Mohd. (1999) New Reproductive Biotechnology, Values and Society In Eubios Journal of Asian and International Bioethics 9. pp. 166-9.

Reproductive Technologies Retrieved on Nov.20, 2007, http://www.leagueforlife.mb.ca/Reprod tech.htm.

Richardson, Diane. (1993) Women, Motherhood, and Childbearing, Macmillan, London.

Schuklenk, Udo and Ashcroft, Richard. (2000) The Ethics of Reproductive and Therapeutic Cloning (research), Monash In Bioethics Review 19(2): 34-45.

The Holy Quran. (1946). Translation and Commentary by A. Yusuf Ali, Sura 23:12-14, Sura 42:50.

YA,Wang. (1996) Infertility and reproductive technology in Access: Australia's National Infertility Network, Infertility: A Fact Sheet for Relatives and Friends (Pamphlet).

Asma Manzoor is Lecturer at Centre of Excellence for Women's Studies, University of Karachi, Pakistan. She is enrolled in M.Phil/ Ph.D. Her areas of interest are: Women and 
Islam, Women and Law, Gender and Development, Women's History in South Asia and Women in Third World Countries.

Saba Imran Ali is Lecturer at Centre of Excellence for Women's Studies, University of Karachi, Pakistan. She is enrolled in M.Phil/ Ph.D. Her areas of interest are: Women and Psychology, Women's Movement, and Women's History in South Asia. 